\title{
Mobile health applications for osteoporosis support available on the market: A systematic review
}

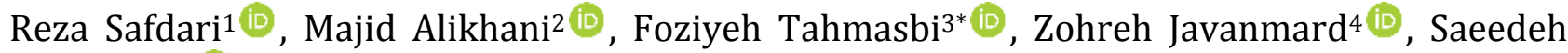 \\ Heydarian $^{5}$ (i) \\ 1Professor, Department of Health Information Management, School of Allied Medical Sciences, Tehran University of Medical Sciences, Tehran, \\ Iran \\ ${ }^{2}$ Assistant Professor, Rheumatology Research Center, Shariati Hospital, Tehran University of Medical Sciences, Tehran, Iran \\ ${ }^{3} \mathrm{Ph} . \mathrm{D}$. Student of Health Information Management, School of Health Management and Information Sciences, Iran University of Medical Sciences, \\ Tehran, Iran \\ ${ }^{4}$ Department of Health Information Technology, Ferdows Paramedical School, Birjand University of Medical Sciences, Birjand, Iran \\ ${ }^{5}$ School of Allied Medical Sciences, Tehran University of Medical Sciences, Tehran, Iran
}

\begin{tabular}{ll}
\hline Article Info & A B S T R A C T \\
\hline $\begin{array}{l}\text { Article type: } \\
\text { Review }\end{array}$ & $\begin{array}{l}\text { Introduction: The use of mobile applications (apps) become widespread } \\
\text { and Provide many benefits especially in healthcare. According to the World }\end{array}$ \\
& Health Organization, osteoporosis is one of the most common diseases of \\
Article History: & elderly in the world. Like other chronic conditions, disease self-management \\
Received: $2020-09-10$ & can prove fruitful. Using a mobile application for Osteoporosis can improve \\
Accepted: $2020-10-13$ & patient care and self-management by encouraging patients to take a more \\
Published: $2020-10-14$ & active role in their health.
\end{tabular}

\begin{tabular}{l}
\hline * Corresponding author: \\
Foziyeh Tahmasbi \\
Ph.D. Student of Health Information \\
Management, School of Health \\
Management and Information \\
Sciences, Iran University of Medical \\
Sciences, Tehran, Iran
\end{tabular}

Email:fo.tahmaseb@gmail.com

Keywords:
m-Health
Self-Management
Osteoporosis
Mobile Applications

Material and Methods: This study presents a systematic review of mHealth applications, available on Google Play Store, Bazaar market (as a local market) and also Apple App Store, for both the English and Persian speakers. The assessment criteria, including content, visual aids, reminders, health warnings, social and design of selected apps, were tested during July 2019.

Results: Reviewing the 19 included applications showed that the most and least focus of apps content was on exercise with $84 \%$ repetition and the osteoporosis fracture that no program addressed this issue separately. Findings on reminders, health warnings, and visual aids were not very encouraging (available in 11\% apps). Reminders were more common in English-speaking apps than Persian-speaking ones, and Visual aids, one of the benefits of mobile apps over paper logbooks, were provided only in2 apps. The opportunity to share data in social networks was available in $26 \%$ of apps, and in the design section, most of the apps have no significant flaws, but $74 \%$ of cases did not provide any clear instructions required for the elderly.

Conclusion: The review shows that there are rather few products on offer and the ones that are available display low quality, poor performance, and evidence-based information is also insufficiently used. Further efforts are required to collect data that will support the design of validated evidencebased educational functions for mHealth apps.

\section{Cite this paper as:}

Safdari R, Alikhani M, Tahmasbi F, Javanmard Z, Heydarian S. Mobile Health Applications for Osteoporosis Support Available on the Market: A Systematic Review. Front Health Inform. 2020; 9: 47. DOI: 10.30699/fhi.v9i1.240

\section{INTRODUCTION}

The use of mobile applications (apps) has become widespread and has given many benefits. In this case, many would argue that professionals and customers have entered the era of mobile health (mHealth) in which mobile technologies play a much larger role in healthcare $[\underline{1}, \underline{2}]$. The industry of these apps is expanding rapidly []ㅡ. The number of apps for two leading app stores, Google Play Store and Apple's App Store, are 2.57 and 1.84 million respectively, among which a lot are medical or healthcare apps [믄 $\underline{5}]$. Mhealth provided many functions and opportunities. They make a new way to promote disease prevention, facilitate the transition of care beyond the hospital setting to the home of patients, and also improve the 
management of chronic diseases. In the same way, mhealth can reduce costs, increase access to services, and improve patient care and self-management by encouraging patients to take a more active role in their health [으-11].

In particular, M-Health Apps will provide advantages for osteoporosis [12]. Osteoporosis is a serious condition and has been announced by the World Health Organization as the four main enemies of human health. It happens as a result of the aging process that bones are weakened in composition and structure $[\underline{13}, \underline{14}]$. Due to the fact that populations around the world are rapidly aging, serious consideration is required, especially in Iran [15]. According to United Nations, the number of people over the age of 65 in the world will increase from $11 \%$ to $22 \%$ (more than 2 billion people) in 2050; in this report, Iran is the third country at the population aging rate after the Arab Emirates and Bahrain [16]. Osteoporosis would bring out many problems and poses a substantial economic burden to health systems, patients, and their families [17]. Despite the fact that osteoporosis is a preventable and manageable condition, the rate of appropriate investigation and management of patients with osteoporosis is very low and the majority of individuals who sustain fragility fractures, which is the most significant concern in osteoporosis, are not receiving adequate management [18]. The individual responsibility for health and self-management of chronic diseases is a concept with growing interest during the last decades and $m$-health can be useful for this purpose $[\underline{19}, \underline{20}]$. Recent findings from Jakobsen et al. study suggest that m-health apps have the potential to support osteoporosis self-management and enabled women diagnosed with asymptomatic osteoporosis to feel confident [21].

However, many of the available mHealth apps are of low quality, even those that are highly rated [19-21]. These may have significant effects and can pose different types of risks to users [18]. For example, a recent study found that a mobile app claiming to provide diagnostic recommendations for suspected melanoma had very low sensitivity and was therefore likely to miss many melanomas [22] The main aim of this contribution is to present a review of the current offer of mHealth devices for osteoporotic patients support for the Persian-speaking and Englishspeaking public. The reason for concentrating on this topic is that the review is a preparatory step towards the development and test of a mobile application to support osteoporotic patients with a fragility fracture in the context of a research project at Tehran University of medicine in Tehran (Iran). Moreover, testing the app in the Iranian context is considered as a first step towards an extension of the device also to other contexts. Based on this review, we are particularly interested to answer the following questions: how many apps are there?; what kind?; which functions do they have?; and especially, given the relevance of self-management and educationoriented functionalities, how do these apps integrate these components?

\section{MATERIAL AND METHODS}

In our review, we searched the apps available for the Persian-speaking and English-speaking public, downloaded, and tested them. Apps were identified through a search in Google Play Store (GPS) and Bazaar market (BM as a local market) (for the Android mobile operating system) and Apple App Store (AAP) (for the IOS mobile operating system) during July 2019. We considered the first 60 entries on all stores for each of the following keywords: "Osteoporosis", "Osteoporotic Fracture "and "Fracture" by itself in both Persian and English.

We selected the apps using the following criteria:

\section{Inclusion criteria}

- Apps that have English/Persian-language user interfaces;

- App used for osteoporosis and osteoporotic fractures

- Apps designed to be used primarily by patients

- Apps designed (also) for pain relief or physiotherapy Exercises

\section{Exclusion criteria}

- Apps that have non-English or non-Persian user interface

- Apps designed to be used by doctors and/or other care professionals;

- Apps that are not primarily designed for osteoporosis self-management (e.g., recipe apps; advertising apps, such as Health saver, augmented reality apps such as osteoporosis AR);

- Apps which are not free for download (including those with free downloads for basic subscriptions, with additional fees for extra features);

- Apps provided by healthcare facilities requiring login;

- Duplicated apps.

The test

The apps were installed and used for a month. Finally, 
the authors observed the apps' responses by focusing on both verbal and visual dimensions.

\section{Assessment criteria}

The reported design, content, and functions of the 19 selected apps were reviewed. Specifically, Apps were analyzed according to chronic disease management model $[\underline{23}, \underline{24}]$, that focuses on Patient We analyzed education and reminders besides some criteria extracted from related studies [25, 26] , so we have considered the following:

Content: Materials and instruction provide patients with information about their condition and how it could be managed.

Reminders: What encourages patients to perform specific tasks related to the care of the condition?

Visual aids: functions aimed at providing visual feedback and display patient performance

Health warnings: evaluating the patient's condition and providing patients with messages and information about their condition.

Social: the function that supports the sharing of information and ideas with others in social networks

Design: is a multi-dimensional criterion and can be viewed from different perspectives. We considered the 3 dimensions based on Nielsen's 10 usability heuristics for user interface design, which were considered to be the most frequent defects in mobile apps:

Error prevention: a careful design which prevents a problem from occurring in the first place
Recognition rather than recall: the ability to minimize the memory load of users, such as remembering patient choices, and providing visible and easily retrievable instructions on how to use the system.

Aesthetic and minimalist design: avoid providing irrelevant or rarely required information [그, 28].

\section{RESULTS}

In the first step, 49 GPS apps, 29 BM apps, and 43 AAS apps were included, of which only 29 were eligible. Of the 92 rejected apps, about $21 \%$ do not have English nor Persian-language user interface(89\% for Android category and $11 \%$ for IOS category), $20 \%$ are paid app(89\% for Android category $11 \%$ for IOS category) $4 \%$ are apps need $\operatorname{login}(25 \%$ for Android category and $75 \%$ for IOS category), 34\% are not app designed for the task of osteoporosis self-management (29\% for Android category $71 \%$ for IOS category) and 21\% not designed for patients ( $42 \%$ for Android category $58 \%$ for IOS category). The total number of eligible apps is 12 for the GPS, 14 for the BM, and 3 for the AAS of which, 3 are duplicate apps (GPS and BM have 2 , and GPS and AAS have 1 in common) and were thus left out. Besides, due to the similar design, identical reference, and overlapping content in $10 \mathrm{BM}$ apps, (2 with reference to www.beytoote.com include "Prevention of Osteoporosis" and "Fight Osteoporosis" and 8 with reference to www.hidoctor.com include "Bone Health (3 version)", "Bone diseases (2 version)", "Bone”, "Bone Secret" and "Bone Care") the first results were used, and the rest were omitted. Overall, the final selection is 19 apps. Fig 1 shows the details of this selections.

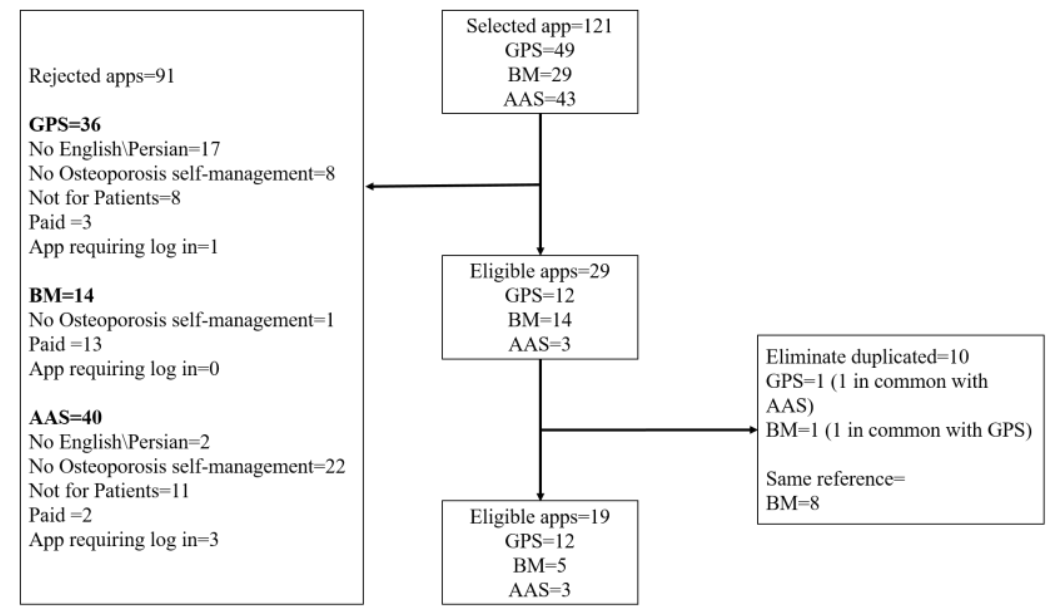

Fig 1: App selection process and result

Table 1 shows the characteristics and functionalities of the tested apps. Technical information is described in the first three columns: for each app, the table shows whether it is available on the GPS, BM, AAS, and sometimes on both; the version number; the average rating. The following six columns are for data entry or content (Diet, Exercise, Diagnosis, Medication, and Fracture), followed by eight other features described above. 
Table 1: Data abstraction of reviewed apps

\begin{tabular}{|c|c|c|c|c|c|c|c|c|c|c|c|c|c|c|c|c|}
\hline \multirow[t]{2}{*}{ Application } & \multirow{2}{*}{$\dddot{0}_{0}^{0}$} & \multirow{2}{*}{ 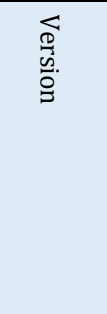 } & \multirow{2}{*}{ 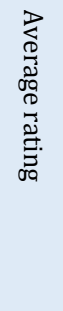 } & \multicolumn{6}{|c|}{ Content } & \multirow{2}{*}{$\begin{array}{l}\pi \\
0 \\
0 \\
3 \\
0 \\
0 \\
0 \\
0 \\
0\end{array}$} & \multirow{2}{*}{ 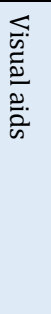 } & \multirow{2}{*}{ 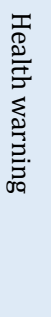 } & \multirow{2}{*}{$\begin{array}{l}\mathscr{n} \\
\stackrel{0}{2}\end{array}$} & \multirow{2}{*}{ 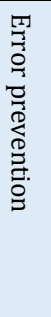 } & \multirow{2}{*}{ 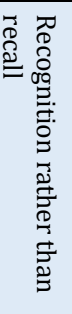 } & \multirow{2}{*}{ 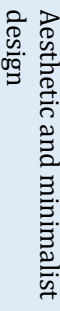 } \\
\hline & & & & 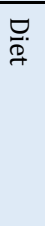 & 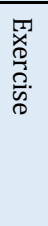 & 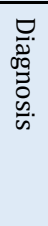 & 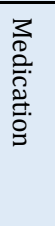 & 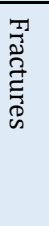 & 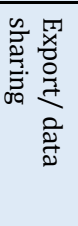 & & & & & & & \\
\hline $\begin{array}{l}\text { Fight } \\
\text { Osteoporosis }\end{array}$ & GPS, BM & 3 & - & Y & Y & $\mathrm{N}$ & $\mathrm{N}$ & $\mathrm{N}$ & Y & $\mathrm{N}$ & $\mathrm{N}$ & $\mathrm{N}$ & $\mathrm{N}$ & $\mathrm{Y}$ & $\mathrm{N}$ & Y \\
\hline $\begin{array}{l}\text { Osteoporosis } \\
\text { cure naturally }\end{array}$ & GPS & 2 & 3.8 & Y & Y & $\mathrm{N}$ & $\mathrm{Y}$ & $\mathrm{N}$ & Y & $\mathrm{N}$ & $\mathrm{N}$ & $\mathrm{N}$ & $\mathrm{N}$ & $\mathrm{Y}$ & $\mathrm{Y}$ & $\mathrm{N}$ \\
\hline $\begin{array}{l}\text { Osteoporosis } \\
\text { disease }\end{array}$ & GPS & 1 & 3.0 & $\mathrm{~N}$ & $\mathrm{~N}$ & Y & $\mathrm{Y}$ & $\mathrm{Y}$ & $\mathrm{N}$ & $\mathrm{N}$ & $\mathrm{N}$ & $\mathrm{N}$ & $\mathrm{N}$ & $\mathrm{Y}$ & $\mathrm{N}$ & $\mathrm{N}$ \\
\hline $\begin{array}{l}\text { Osteoporosis } \\
\text { info }\end{array}$ & GPS & 1. & 5 & Y & Y & Y & $\mathrm{Y}$ & $\mathrm{Y}$ & $\mathrm{N}$ & $\mathrm{N}$ & $\mathrm{N}$ & $\mathrm{N}$ & $\mathrm{N}$ & $\mathrm{Y}$ & $\mathrm{Y}$ & Y \\
\hline $\begin{array}{l}\text { Osteoporosis } \\
\text { cure }\end{array}$ & GPS & 1 & - & Y & Y & Y & $\mathrm{Y}$ & $\mathrm{Y}$ & $\mathrm{N}$ & $\mathrm{N}$ & $\mathrm{N}$ & $\mathrm{N}$ & $\mathrm{N}$ & $\mathrm{Y}$ & $\mathrm{N}$ & $\mathrm{N}$ \\
\hline My arthritis & GPS & 2.30 .46 & - & Y & Y & Y & $\mathrm{Y}$ & $\mathrm{Y}$ & $\mathrm{N}$ & $\mathrm{Y}$ & $\mathrm{Y}$ & $\mathrm{Y}$ & $\mathrm{Y}$ & $\mathrm{N}$ & Y & Y \\
\hline Osteoporosis & GPS & 1.0 & 5 & Y & Y & Y & $\mathrm{Y}$ & $\mathrm{N}$ & $\mathrm{N}$ & $\mathrm{N}$ & $\mathrm{N}$ & $\mathrm{N}$ & $\mathrm{N}$ & $\mathrm{Y}$ & $\mathrm{N}$ & Y \\
\hline $\begin{array}{l}\text { All bone } \\
\text { diseases }\end{array}$ & GPS & 1.78 & 4.0 & Y & Y & Y & $\mathrm{N}$ & $\mathrm{N}$ & $\mathrm{N}$ & $\mathrm{N}$ & $\mathrm{N}$ & $\mathrm{N}$ & $\mathrm{N}$ & $\mathrm{Y}$ & $\mathrm{N}$ & $\mathrm{N}$ \\
\hline The spine app & GPS & 1.1 & 3.7 & $\mathrm{~N}$ & Y & $\mathrm{N}$ & $\mathrm{N}$ & $\mathrm{N}$ & Y & $\mathrm{N}$ & $\mathrm{N}$ & $\mathrm{N}$ & $\mathrm{N}$ & $\mathrm{Y}$ & $\mathrm{N}$ & Y \\
\hline Fracture & GPS & 1.1 & 3.7 & $\mathrm{~N}$ & $\mathrm{~N}$ & $\mathrm{Y}$ & $\mathrm{N}$ & $\mathrm{Y}$ & $\mathrm{N}$ & $\mathrm{N}$ & $\mathrm{N}$ & $\mathrm{N}$ & $\mathrm{N}$ & $\mathrm{Y}$ & $\mathrm{N}$ & Y \\
\hline $\begin{array}{l}\text { Lower back pain } \\
\text { Exercise }\end{array}$ & GPS & 2.0 .1 & 4.5 & $\mathrm{~N}$ & Y & $\mathrm{N}$ & $\mathrm{N}$ & $\mathrm{N}$ & $\mathrm{N}$ & $\mathrm{N}$ & $\mathrm{N}$ & $\mathrm{N}$ & $\mathrm{N}$ & $\mathrm{Y}$ & $\mathrm{N}$ & Y \\
\hline Osteoporosis & BM & 1.1 .7 & 4.3 & Y & Y & $\mathrm{N}$ & $\mathrm{N}$ & $\mathrm{N}$ & $\mathrm{Y}$ & $\mathrm{N}$ & $\mathrm{N}$ & $\mathrm{N}$ & $\mathrm{N}$ & $\mathrm{Y}$ & $\mathrm{N}$ & Y \\
\hline $\begin{array}{l}\text { Prevention of } \\
\text { Osteoporosis }\end{array}$ & BM & 1.0 & 5.0 & Y & Y & $\mathrm{N}$ & $\mathrm{N}$ & $\mathrm{N}$ & Y & $\mathrm{N}$ & $\mathrm{N}$ & $\mathrm{N}$ & $\mathrm{N}$ & $\mathrm{Y}$ & $\mathrm{N}$ & Y \\
\hline Bone Health & BM & 1 & 4.8 & Y & Y & $\mathrm{Y}$ & $\mathrm{N}$ & $\mathrm{N}$ & $\mathrm{Y}$ & $\mathrm{N}$ & $\mathrm{N}$ & $\mathrm{N}$ & $\mathrm{N}$ & $\mathrm{Y}$ & $\mathrm{N}$ & $\mathrm{N}$ \\
\hline $\begin{array}{l}\text { Osteoporosis } \\
\text { and } \\
\text { consultation }\end{array}$ & BM & 1 & 4.7 & Y & Y & Y & $\mathrm{N}$ & $\mathrm{Y}$ & Y & $\mathrm{N}$ & $\mathrm{N}$ & $\mathrm{N}$ & $\mathrm{Y}$ & $\mathrm{Y}$ & $\mathrm{N}$ & Y \\
\hline Healthy Bone & BM & 3.1 & - & Y & Y & Y & $\mathrm{N}$ & $\mathrm{N}$ & $\mathrm{N}$ & $\mathrm{N}$ & $\mathrm{N}$ & $\mathrm{N}$ & $\mathrm{N}$ & $\mathrm{Y}$ & $\mathrm{N}$ & $\mathrm{N}$ \\
\hline $\begin{array}{l}\text { Osteoporosis by } \\
\text { Azo medical }\end{array}$ & AAS & 2.1 & $\mathrm{~N}$ & $\mathrm{Y}$ & Y & Y & Y & $\mathrm{Y}$ & Y & $\mathrm{N}$ & $\mathrm{N}$ & $\mathrm{N}$ & $\mathrm{Y}$ & $\mathrm{Y}$ & $\mathrm{N}$ & Y \\
\hline $\begin{array}{l}\text { My } \\
\text { Osteoporosis } \\
\text { Manager }\end{array}$ & AAS & 10.0 .0 & $\mathrm{~N}$ & $\mathrm{~N}$ & $\mathrm{~N}$ & Y & Y & $\mathrm{N}$ & Y & $\mathrm{Y}$ & $\mathrm{Y}$ & $\mathrm{Y}$ & $\mathrm{Y}$ & $\mathrm{Y}$ & $\mathrm{Y}$ & Y \\
\hline My Osteoteam & AAS, GPS & 11.7 .0 & 1 & $\mathrm{Y}$ & Y & Y & Y & $\mathrm{Y}$ & $\mathrm{N}$ & $\mathrm{N}$ & $\mathrm{N}$ & $\mathrm{N}$ & $\mathrm{Y}$ & $\mathrm{N}$ & Y & $\mathrm{N}$ \\
\hline
\end{tabular}

In the area of reminder, warning, and visual aids, only 2 apps (My arthritis from GPS and My Osteoporosis Manager from AAS) were able to meet study criteria such as sending prompt messages, evaluating user status, or providing any graphs, diagrams, tables or statistics as a visual feedback, and $89 \%$ were incapable. In the design part, $26 \%$ of apps have errors such as low speed or ineffective buttons. Table 2 summarizes the results of this study. 
Table 2: Results for assessment criteria in the reviewed apps

\begin{tabular}{|l|c|c|c|}
\hline Features and functions & Yes & No & $\%$ \\
\hline Diet & 14 & 5 & 74 \\
\hline Exercise & 16 & 3 & 84 \\
\hline Diagnosis & 13 & 6 & 68 \\
\hline Medication & 9 & 10 & 47 \\
\hline Fractures & 8 & 11 & 42 \\
\hline Data sharing & 9 & 10 & 47 \\
\hline Reminder & 2 & 17 & 11 \\
\hline Visual aids & 2 & 17 & 11 \\
\hline Health warnings & 2 & 17 & 11 \\
\hline Social & 5 & 14 & 26 \\
\hline Error prevention & 14 & 5 & 74 \\
\hline Recognition rather than recall & 5 & 14 & 26 \\
\hline Aesthetic and minimalist design & 13 & 7 & 68 \\
\hline
\end{tabular}

\section{DISCUSSION}

Self-management can help to manage the increasing burden of chronic diseases [29]. Interventions to support patients' self-management, were most strongly associated with improvements in patient process outcomes [일. In this study, we consider to review the apps available in the market, developed to support the self-management of Osteoporosis, by considering some required aspects according to chronic disease management model along with features stated by Hoyt that were explained before. Many reviews have already underlined the lack of educational functions in the majority of m-health apps $[\underline{18}-21, \underline{25}, \underline{31}]$. In the same vein, these results are also confirmed by our review. However, patient information is a key component of effective selfmanagement in relation to osteoporosis and fracture preventions but information given at one point maybe too much to take in and an study showed that osteoporosis consultations contain too much of focus on pharmaceutical intervention than nonpharmaceutical one like diet and exercise which exactly opposite in terms of applications content in our review that The most focus of apps content was on exercise with $84 \%$ repetition which was predictable given that "Osteoporosis exercise" is the preferred term in the GPS [르]. So may be these two could cover each other gaps. In evaluating the content section of the applications, also it was found that the least amount of attention was paid to the osteoporosis fracture section, and no program addressed this issue separately despite the fact that osteoporosis fracture is the most important complication of osteoporosis in the elderlies [33]. Findings on Reminders, health warnings, and visual aids were not very encouraging. Patient reminders are important in chronic diseases [24, 34]. Studies have shown that systems with computerized recall and reminders interventions have benefit on patient level outcome [24, 35]. Moreover, for one thing, maintaining medical adherence in older adults with chronic diseases ensures that treatment is effective and, because of forgetfulness, reminders are needed [36]. The result of our study also showed that reminders in English-speaking apps are more common than Persian-speaking ones, which was the same with findings of $\mathrm{Wu}$ and et.al that concluded personal feedback and reminders were more popular in US apps than the Chinese ones [37]. Seeing images, graphs and generally visual aids presentation can improve the ease with which the users and the product interact and therefore the usability of that and in the study of Raybould et.al participant with osteoporosis mentioned that they asked for diagram and visual images $[\underline{32}, \underline{38}]$. By the way, they are one of the advantages that mobile apps offer to patients upgrading from paper logbook to an electronic system, but in this study, only 2 apps provide this feature appropriately [39]. Similarly, data sharing, which is a good way to give feedback and facilitate interaction among patients, clinicians, researchers, and vendors, was provided in 5 apps. This finding is consistent with that of Kim (2018), who reviewed apps for drug-drug interaction check, and only 5 of the 23 reviewed apps provided this function [36]. Again, the results of evaluating the design part, which took more time particularly in the field of error prevention, indicated that most of the apps had no serious errors, but $74 \%$ of cases did not provide clear instructions that were necessary for the elderly. A possible explanation for this might be the lack of intelligence and the fact that most systems are onedimensional in the delivery of information [40]. Also the fact that apps today frequently use active data entry like surveys instead of passive one such as smartphone sensors, GPS or call/text log [41]. Nevertheless, in this research, the presence of instructions or the probability of recalling the last studied page also distinguished between that app and others. Finally, the most critical aspect of aesthetics was the irrelevant details found in 7 apps (32\%), and as stated earlier, most of the apps available, particularly in BM, have the same websites with a low information value as the reference. These results also support the work of Alessa et al. who found that the most of the existing apps are weak in terms of information resources. They have studied selfmanagement applications in hypertension and have shown that few applications can perform well [42]. Our study also confirmed the result of Wisniewski et.al study that stated there is no correlations between star rating of an app and function of it [41].

\section{CONCLUSION}

This study reviewed 19 apps developed to support the self-management of Osteoporosis. Management of chronic disease requires that patients take a more active role in the day-to-day decisions about the 
management of their illness. Our study shows that most of the apps have low quality, poor performance, and evidence-based information is also insufficiently used. A possible explanation for these results may be: 1 - the lack of clean and acceptable standards for the development of apps [18]; 2- the lack of analysis tools (which according to the study by Erfani et.al. in $80 \%$ of cases the developers are also a tester) [43]; and 3the fact that everybody can develop medical apps of the content don't have strong references that can bring out many risks [18]. A limitation of this study is that the review was conducted without considering paid apps, which may benefit, from a higher level of free apps. But in reality, cost is the primary criterion for the choice of the app. Moreover, the importance of public access to health information and the fact that $80 \%$ of disease-related deaths are prevalent in lowincome countries [44], indicate the need for free access to m-health applications. Further efforts are required to collect data that will support the design of validated evidence-based educational functions for mHealth apps.

\section{ACKNOWLEDGEMENTS}

This study was part of an MSc thesis supported by Tehran University of Medical Sciences under grant no.280/3/F/104. The authors would like to gratefully acknowledge all who contributed to this study.

\section{AUTHOR'S CONTRIBUTION}

(I) Conception and design: Reza Safdari, Foziyeh Tahmasbi, (II) Administrative support: Reza Safdari, (III) Collection and assembly of data: All Authors, (IV) Data analysis and interpretation: All authors, (V) Manuscript writing: All authors, (VI) Final approval of manuscript: All authors.

\section{CONFLICTS OF INTEREST}

The authors declare no conflicts of interest regarding the publication of this study.

\section{FINANCIAL DISCLOSURE}

No financial interests related to the material of this manuscript have been declared.

\section{REFERENCES}

1. Yavari K, Basakha M, Sadeghi H, Naseri AR. Economic aspects of ageing. Iranian Journal of Ageing. 2015; 10(1): 92-105.

2. Demontiero O, Vidal C, Duque G. Aging and bone loss new insights for the clinician. Ther Adv Musculoskelet Dis. 2012; 4(2): 61-76. PMID: 22870496 DOI: $10.1177 / 1759720 X 11430858$ [PubMed]

3. World Health Organization [Internet]. Aging and life course. 2018 [cited: 21 Aug 2019]. Available from: https://www.who.int/ageing/en/

4. Sharifi N, Majlessi F, Montazeri A, Shojaeizadeh D, Sadeghi R. Prevention of osteoporosis in female students based on the Orem self-care model. Electron Physician. 2017; 9(10): 5465-71. PMID: 29238485 DOI: $10.19082 / 5465$ [PubMed]

5. Choi W, Zheng H, Franklin P, Tulu B. mHealth technologies for osteoarthritis self-management and treatment: A systematic review. Health Informatics J. 2019; 25(3): 984-1003. PMID: 29090628 DOI: 10.1177/1460458217735676 [PubMed]

6. Sözen T, Özışık L, Başaran NÇ. An overview and management of osteoporosis. Eur J Rheumatol. 2017; 4(1): 46-56. PMID: 28293453 DOI: 10.5152/eurjrheum.2016.048 [ $\underline{\text { PubMed] }}$

7. Hamine S, Gerth-Guyette E, Faulx D, Green BB, Ginsburg AS. Impact of mHealth chronic disease management on treatment adherence and patient outcomes: A systematic review. J Med Internet Res 2015; 17(2):e52. PMID: 25803266 DOI: 10.2196/jmir.3951 [PubMed]
8. Mohammadzadeh N, Safdari R. Patient monitoring in mobile health: opportunities and challenges. Med Arch. 2014; 68(1): 57-60. PMID: 24783916 DOI: 10.5455/medarh.2014.68.57-60 [PubMed]

9. Haute Autorité de santé [Internet]. Good practice guidelines on health apps and smart devices (mobile health or mHealth). 2016 [cited: 27 Dec 2019]. Available from: https://www.hassante.fr/upload/docs/application/pdf/201703/dir1/good_practice_guidelines_on_health _apps_and_smart_devices_mobile_health_or_mhealth. pdf

10. Wu F, Laslett LL, Wills $\mathrm{K}$, Oldenburg B, Jones G, Winzenberg T. Effects of individualized bone density feedback and educational interventions on osteoporosis knowledge and self-efficacy: A 12-yr prospective study. J Clin Densitom. 2014; 17(4): 46672. $\quad 25220886$ PMID: 10.1016/j.jocd.2014.07.008 [PubMed]

11. Zargarzadeh P, Ehteshami A, Mohammadi-Sichani M. A contribution into developing a model for prostate cancer self-care mobile application. Med Arch. 2018; 72(5): 344-7. PMID: 30524166 DOI: 10.5455/medarh.2018.72.344-347 [ [PubMed]

12. Lu J, Wu D, Mao M, Wang W, Zhang G. Recommender system application developments: A survey. Decision Support Systems. 2015; 74: 12-32.

13. Heijmans M, Waverijn G, Rademakers J, van der Vaart R, Rijken M. Functional, communicative and critical health literacy of chronic disease patients and their importance for self-management. Patient Educ Couns. 2015 Jan;98(1):41-8. PMID: 25455794 DOI: 10.1016/j.pec.2014.10.006 [PubMed] 
14. Ravn Jakobsen P, Hermann AP, Sondergaard J, Kock Wiil U, Clemensen J. Help at hand: Women's experiences of using a mobile health application upon diagnosis of asymptomaticosteoporosis. SAGE Open Med. 2018; 6(1): 1-11. PMID: 30397471 DOI: $10.1177 / 2050312118807617$ [PubMed]

15. Dagan N, Cohen-Stavi C, Leventer-Roberts M, Balicer RD. External validation and comparison of three prediction tools for risk of osteoporotic fractures using data from population based electronic health records: Retrospective cohort study. BMJ. 2017; 356: i6755. PMID: 28104610 DOI: $10.1136 / \mathrm{bmj} .16755$ [PubMed]

16. Wildenbos GA, Jaspers MWM, Schijven MP, DusseljeePeute LW. Mobile health for older adult patients: Using an aging barriers framework to classify usability problems. Int J Med Inform. 2019; 124: 68$77 . \quad$ PMID: 30784429 DOI: 10.1016/j.ijmedinf.2019.01.006 [PubMed]

17. Charalambous CP, Mosey C, Johnstone E, Akimau P, Gullett TK, Siddique I, et al. Improving osteoporosis assessment in the fracture clinic. Ann R Coll Surg Engl. 2009; 91(7): 596-8. PMID: 19558771 DOI: 10.1308/003588409X432400 [․ubMed]

18. Van Velthoven MH, Smith J, Wells G, Brindley D. Digital health app development standards: A systematic review protocol. BMJ Open. 2018; 8: e022969. PMID: 30121614 DOI: $10.1136 /$ bmjopen-2018-022969 [PubMed]

19. Rudin RS, Fanta CH, Predmore Z, Kron K, Edelen MO, Landman $\mathrm{AB}$, et al. Core components for a clinically integrated mHealth app for asthma symptom monitoring. Appl Clin Inform. 2017; 8(4): 1031-43. PMID: 29241243 DOI: 10.4338/ACI-2017-06-RA0096 [PubMed]

20. Boudreaux ED, Waring ME, Hayes RB, Sadasivam RS, Mullen S, Pagoto S. Evaluating and selecting mobile health apps: strategies for healthcare providers and healthcare organizations. Transl Behav Med. 2014; 4(4): 363-71. PMID: 25584085 DOI: 10.1007/s13142014-0293-9 [PubMed]

21. Formagini TDB, Ervilha RR, Machado NM, Bottaro de Andrade BAB, Gomide HP, Ronzani TM. A review of smartphone apps for smoking cessation available in Portuguese. Cad Saude Publica. 20179; 33(2): e00178215. PMID: 28300972 DOI: 10.1590/0102311X00178215 [PubMed]

22. Wolf JA, Moreau JF, Akilov O, Patton T, English JC, Ho $J$, et al. Diagnostic inaccuracy of smartphone applications for melanoma detection. JAMA Dermatol. 2013; 149(4): 422-6. PMID: 23325302 DOI: 10.1001/jamadermatol.2013.2382 [ubMed]

23. Zimbudzi E, Lo C, Misso M, Ranasinha S, Zoungas S. Effectiveness of management models for facilitating self-management and patient outcomes in adults with diabetes and chronic kidney disease. Syst Rev. 2015; 4: 81. PMID: 26059649 DOI: 10.1186/s13643-0150072-9 [PubMed]

24. Weingarten SR, Henning JM, Badamgarav E, Knight
$\mathrm{K}$, Hasselblad V, Jr AG, et al. Interventions used in disease management programmes for patients with chronic illness-which ones work? Meta-analysis of published reports. BMJ. 2002; 325(7370): 925. PMID: $12399340 \quad$ DOI: $\quad 10.1136 / \mathrm{bmj} .325 .7370 .925$ [PubMed]

25. Rossi MG, Bigi S. mHealth for diabetes support: a systematic review of apps available on the Italian market. Mhealth. 2017; 3: 16. PMID: 28567412 DOI: 10.21037/mhealth.2017.04.06 [PubMed]

26. Hoyt RE, Cruz RW, Fleury R. Mobile technology and mHealth. Florida: informatics education; 2014.

27. Bright TJ, Bakken S, Johnson SB. Heuristic evaluation of eNote: An electronic notes system. AMIA Annu Symp Proc. 2006; 2006: 864. PMID: 17238484 [PubMed]

28. Nouri R, Rostam Niakan Kalhori S, Ghazisaeedi M, Marchand G, Yasini M. Criteria for assessing the quality of mHealth apps: A systematic review. J Am Med Inform Assoc. 2018; 25(8): 1089-98. PMID: 29788283 DOI: 10.1093/jamia/ocy050 [ubMed]

29. Dennis SM, Zwar N, Griffiths R, Roland M, Hasan I, Davies GP, et al. Chronic disease management in primary care: from evidence to policy. Med J Aust. 2008; 188(S8): S53-6. PMID: 18429737 [PubMed]

30. Grover A, Joshi A. An overview of chronic disease models: A systematic literature review. Glob J Health Sci. 2014; 7(2): 210-27. PMID: 25716407 DOI: 10.5539/gjhs.v7n2p210 [PubMed]

31. Albrecht UV, Von Jan U, Jungnickel T, Pramann O. Appsynopsis-standard reporting for medical apps. Stud Health Technol Inform 2013; 192: 1154. PMID: 23920928 [PubMed]

32. Raybould G, Babatunde O, Evans AL, Jordan JL, Paskins Z. Expressed information needs of patients with osteoporosis and/or fragility fractures: A systematic review. Arch Osteoporos. 2018; 13(1): 55. PMID: $29736627 \quad$ DOI: $\quad 10.1007 / \mathrm{s} 11657-018-0470-4$ [PubMed]

33. Sànchez-Riera L, Wilson N. Fragility fractures \& their impact on older people. Best Pract Res Clin Rheumatol. 2017; 31(2): 169-19. PMID: 29224695 DOI: 10.1016/j.berh.2017.10.001 [PubMed]

34. Zimbudzi E, Lo C, Misso M, Ranasinha S, Zoungas S. Effectiveness of management models for facilitating self-management and patient outcomes in adults with diabetes and chronic kidney disease. Syst Rev. 2015; 4: 81. PMID: 26059649 DOI: 10.1186/s13643-0150072-9 [PubMed]

35. Reynolds R, Dennis S, Hasan I, Slewa J, Chen W, Tian D, et al. A systematic review of chronic disease management interventions in primary care. BMC Fam Pract. 2018; 19(1): 11. PMID: 29316889 DOI: 10.1186/s12875-017-0692-3 [ubMed]

36. Kim BY, Sharafoddini A, Tran N, Wen EY, Lee J. Consumer mobile apps for potential drug-drug interaction check: Systematic review and content analysis using the mobile app rating scale (MARS). 
JMIR Mhealth Uhealth. 2018; 6(3): e74. PMID: 29592848 DOI: $10.2196 /$ mhealth.8613 [PubMed]

37. Wu Y, Zhou Y, Wang X, Zhang Q, Yao X, Li X, et al. A comparison of functional features in Chinese and US mobile apps for diabetes self-management: A systematic search in app stores and content analysis. JMIR Mhealth Uhealth. 2019; 7(8): e13971. PMID: 31464191 DOI: $10.2196 / 13971$ [PubMed]

38. Hood M, Wilson R, Corsica J, Bradley L, Chirinos D, Vivo A. What do we know about mobile applications for diabetes self-management? A review of reviews. J Behav Med. 2016; 39(6): 981-94. PMID: 27412774 DOI: $10.1007 / \mathrm{s} 10865-016-9765-3$ [PubMed]

39. El-Gayar O, Timsina P, Nawar N, Eid W. Mobile applications for diabetes self-management: Status and potential. J Diabetes Sci Technol. 2013; 7(1): 24762. PMID: 23439183 DOI: $10.1177 / 193229681300700130$ [PubMed]

40. Moore S, Tassé AM, Thorogood A, Winship I, Zawati M, Doerr M. Consent processes for mobile app mediated research: Systematic review. JMIR Mhealth Uhealth. 2017; 5(8): e126. PMID: 28855147 DOI: 10.2196/mhealth.7014 [PubMed]

41. Wisniewski H, Liu G, Henson P, Vaidyam A, Hajratalli NK, Onnela JP, et al. Understanding the quality, effectiveness and attributes of top-rated smartphone health apps. Evid Based Ment Health 2019; 22(1): 4-9. PMID: 30635262 DOI: 10.1136/ebmental-2018300069 [PubMed]

42. Alessa T, Hawley MS, Hock ES, de Witte L. Smartphone apps to support self-management of hypertension: Review and content analysis. JMIR Mhealth Uhealth 2019; 7(5): 1-14. PMID: 31140434 DOI: 10.2196/13645 [PubMed]

43. Erfani M, Mesbah, A, Kruchten, P. Real challenges in mobile app development. International Symposium on Empirical Software Engineering and Measurement. IEEE; 2013.

44. Miranda JJ, Kinra S, Casas JP, Davey Smith G, Ebrahim $\mathrm{S}$. Non-communicable diseases in low- and middleincome countries: Context, determinants and health policy. Trop Med Int Health. 2008;13(10):1225-34. PMID: $\quad 18937743$ DOI: $10.1111 /$ j.13653156.2008.02116.x [PubMed] 